\title{
Política Fiscal, Sustentabilidade da Dívida Pública e Liquidez dos Títulos: Uma Análise para o Brasil
}

\author{
- Fernando Motta Correia*
}

- ROBERTO MEURER **

\begin{abstract}
RESUMO
Este artigo trata do esforço fiscal adotado desde 1999 no Brasil, e da importância de um mercado de títulos públicos de liquidez elevada para que o esforço fiscal seja aliviado. É aplicado um modelo baseado em Edwards (2003) para projetar o resultado fiscal primário, levando em consideração diferentes cenários de demanda por títulos, taxa de crescimento real do PIB, meta de inflação, remuneração dos títulos públicos e choques na taxa de câmbio. Com isso, avaliou-se o impacto de alterações na procura pelos títulos públicos sobre o esforço fiscal necessário para estabilizar a proporção dívida/PIB. Os resultados indicam que as alterações na demanda por títulos alteram a sensibilidade do esforço fiscal a alterações na taxa de crescimento do PIB e a mudanças na taxa de câmbio, enquanto as demais variáveis influenciam o esforço fiscal com sensibilidade constante.
\end{abstract}

\section{Palavras-Chave}

política fiscal, dívida pública, Brasil

\begin{abstract}
This article evaluates such a fiscal effort and in particular the role played by the liquidity of the public debt bonds market to alleviate the effort. A model based on Edwards (2003) is applied to forecast the primary fiscal surplus in alternative scenarios of demand for the public debt bonds, real GDP growth, inflation target, real interest rate and changes in exchange rate. We focus on the impact of the changes in demand for the public debt bonds on the fiscal effort necessary to stabilize the debt-GDP ratio. Results show that such changes alter the response of the fiscal effort to GDP growth and changes in exchange rate. Although the other variables considered can affect the fiscal effort their response to GDP growth is constant.
\end{abstract}

\section{KEYWORDS}

fiscal policy, debt, Brazil

\section{JEL ClassifiCATION}

E6, H6, H62

\footnotetext{
+ Os autores agradecem as críticas e sugestões de dois pareceristas anônimos da revista Estudos Econômicos, as quais contribuíram para a melhoria deste trabalho.

* Doutorando do Programa de Pós Graduação em Desenvolvimento Econômico da UFPR. Endereço para contato: R. Pres. Beaurepaire Rohan, 509, BI. I, Apt. 102, Cristo Rei - Curitiba - PR - CEP: 80050-340 E-mail: fmottabr@ yahoo.com.br.

* Professor do Departamento de Economia da UFSC. Endereço para contato: Departamento de Economia - Centro Socioeconômico - UFSC - Florianópolis - SC - CEP: 88040-970. E-mail: rmeurer@mboxl.ufsc.br.

(Recebido em agosto de 2005. Aceito para publicação em junho de 2007).
} 


\section{$1 \quad$ INTRODUÇÃO}

Desde a flutuação cambial e a implantação do Regime de Metas Inflacionárias em 1999, a política fiscal brasileira tem o importante objetivo de evitar que a relação dívida/PIB cresça e procura induzir a uma redução paulatina. $\mathrm{O}$ esgotamento do regime de câmbio semifixo forçou o setor público a gerar superávits primários, na tentativa de superar as pressões provenientes da dinâmica de sua dívida e a escassez de financiamento externo. $\mathrm{O}$ resultado foram superávits primários crescentes, penalizando a capacidade de investimento público.

Embora o ajuste fiscal venha sendo a principal estratégia no gerenciamento da dívida pública, a sua condução tem sido prejudicada pelo perfil da dívida. Ao final de 1997, em função das crises financeiras internacionais houve um incremento expressivo no patamar dos juros internos, que passaram a apresentar grande volatilidade. Com isso, os agentes aumentaram a demanda por títulos públicos pós-fixados, gerando incerteza acerca do serviço da dívida e pondo em dúvida a capacidade futura de pagamento.

Visando se proteger de tais crises financeiras, sobretudo a iniciada no sudeste asiático, em novembro de 1997 o governo federal anunciou um elenco de providências denominado "ajuste fiscal de curto prazo", na tentativa de preservar os benefícios já alcançados pelo Plano Real. O aumento da Dívida Líquida do Setor Público (DLSP), que em dezembro de 1998 alcançou 41,7\% do PIB, contra 34,5\% do PIB em dezembro de 1997, exigia medidas de estabilização da relação dívida/PIB. O Programa de Estabilização Fiscal implementado consistia em obter superávits primários no agregado dos três níveis de governo. O incremento do saldo primário do governo em relação ao PIB entre 1998 e 1999 indica a dinâmica que seria seguida para a política fiscal a partir desse ano, refletindo o ajuste às mudanças no cenário de financiamento externo e o acordo com o FMI. ${ }^{1}$ Se por um lado o abrangente plano de estabilização fiscal implementado no Brasil a partir de 1999 tenha buscado diminuir os desequilíbrios fiscais e o resgate da credibilidade da política fiscal, o perfil da dívida pública tornou-se um dos principais problemas no gerenciamento da esfera fiscal.

l Segundo relatório da OCDE, o conjunto de reformas em novembro de 1998, implementado após a crise, baseou-se no programa plurianual de ajustamento fiscal (1999-2001), estabelecendo metas de superávit primário consolidado do setor público em $3,1 \%$ do PIB para 1999, 3,25\% para 2000 e 3,35\% para 2001. Em contrapartida, credores oficiais, multilaterais e bilaterais concederam assistência financeira superior a US\$ 41 bilhões. Esse programa, acordado com o Fundo Monetário Internacional (FMI) para o período 1999-2000, disponibilizou aproximadamente US\$ 37 bilhões nos primeiros doze meses. As metas de superávit primário para 1999-2001 foram alcançadas com folga. 
Assim, junto à necessidade de geração de superávits primários nas contas públicas, o Tesouro Nacional começou a implementar medidas com o objetivo de melhorar o perfil da dívida pública, sobretudo a partir de 2005. Dentre as medidas, segundo a Secretaria do Tesouro Nacional, podemos destacar: (i) organização dos vencimentos dos títulos em meses específicos (benchmarks), visando aumentar a liquidez e melhorar a precificação dos mesmos; (ii) operações de troca de títulos de curto prazo por prazos mais longos; (iii) realização de resgates antecipados, buscando reduzir o risco de refinanciamento e, no caso dos títulos indexados à inflação, também visando ao aumento da liquidez nesse mercado; (iv) melhora do saldo de caixa do Tesouro Nacional, mantendo o "colchão de liquidez" da dívida pública em níveis seguros; e (v) medidas para ampliação da base de investidores.

O foco deste artigo é a política fiscal brasileira, mostrando a necessidade de se ter um mercado de títulos públicos de liquidez elevada para que o esforço fiscal seja aliviado. Além dessa introdução, o artigo contempla mais três seções. A seção 2 trata do aspecto metodológico, em que é apresentado, a partir de uma relação contábil, um modelo baseado em Edwards (2003) a partir do qual é possível construir várias trajetórias para o saldo primário do governo requerido para estabilizar a proporção dívida/PIB, levando em consideração diferentes cenários de demanda por títulos públicos, taxa de crescimento real do PIB, meta de inflação, remuneração dos títulos públicos e choques cambiais. A seção 3 apresenta os resultados das projeções do modelo, avaliando o impacto de alterações na demanda por títulos sobre o esforço fiscal necessário para manter a dívida pública sustentável. Por fim, as conclusões apontam propostas para a política fiscal brasileira.

\section{UM MODELO PARA ANÁLISE DO AJUSTE FISCAL}

\subsection{Uma discussão sobre Sustentabilidade da dívida pública}

O debate sobre a posição de endividamento do setor público envolve, antes de tudo, a análise da restrição orçamentária (de longo prazo) do governo. Como tal restrição compreende os valores presentes de toda a evolução de despesas e receitas, de modo que o valor presente dos gastos públicos, $G$, deve ser menor ou igual à soma da sua riqueza inicial (ou dívida a pagar), $-D$, mais o valor presente dos tributos a receber (descontadas as transferências), $T$.

A equação a seguir (ROMER, 2000), expressa de forma clara o conceito de restrição orçamentária: 


$$
\int_{t=0}^{\infty} e^{-R(t)} G(t) d t \leq-D(0)+\int_{t=0}^{\infty} e^{-R(t)} T(t) d t
$$

Podemos reescrever essa restrição orçamentária de outra forma:

$$
\int_{t=0}^{\infty} e^{-R(t)}[T(t)-G(t)] d t \geq D(0)
$$

Esta equação indica que o governo tem de obter superávits primários para compensar a dívida inicial. Todavia, na análise dos indicadores fiscais sobre a posição/volume de endividamento público, deve-se levar em consideração que a redução da taxa de crescimento da dívida pública, ou mesmo sua estabilidade, nem sempre depende de uma decisão autônoma do governo, mas freqüentemente de um conjunto de variáveis determinantes da trajetória da relação Dívida/PIB. Conforme ressaltado por Batista Jr.(1989), se não houver como acelerar o crescimento da economia - e obter uma redução da taxa de juros ou da dívida existente - e se a senhoriagem for constante ou decrescente, a possibilidade de conter o crescimento da dívida e do seu serviço passa a depender do aumento do superávit primário, isto é, da redução dos gastos não-financeiros, da elevação da carga tributária ou de uma combinação das duas alternativas.

Em razão disso, o conceito de sustentabilidade da dívida pública é aqui entendido, de acordo com Buiter (1985), a partir da hipótese de que uma política fiscal pode ser considerada sustentável se é possível manter constante a relação entre a dívida líquida do setor público e o PIB.

No Brasil, os trabalhos que utilizaram testes empíricos e indicadores de sustentabilidade fiscal, segundo Borges (2006), consideram que a dívida pública é sustentável no período preestabilização, fase esta em que se utilizava a senhoriagem como meio de financiamento dos déficits. Com a implantação do Plano Real, viu-se o estreitamento das fontes inflacionárias de financiamento do setor público, de modo que nessa fase pós-estabilização, grande parte dos trabalhos considera que a dívida pública assume uma trajetória insustentável. ${ }^{2}$

Assim, dada a restrição orçamentária intertemporal do governo, o controle do endividamento público (relação Dívida/PIB) define, dependendo do comportamento

2 Para estudos empíricos sobre sustentabilidade fiscal no Brasil, ver Pastore (1995), Rocha (1997), Bevilaqua e Werneck (1997), Issler e Lima (1998), Luporini (2001), Gamboa e Silva (2004), Giambiagi e Ronci (2004). 
da taxa de crescimento da economia, da taxa de juros e da senhoriagem, o esforço fiscal necessário para que a relação Dívida/PIB seja sustentável.

Para responder a essa questão, trataremos a seguir de um modelo analítico, tendo por base o trabalho de Edwards (2003), segundo o qual será possível identificar os efeitos das mudanças na taxa de crescimento real da economia, taxa de juros, meta de inflação, taxa de câmbio e na demanda por títulos públicos sobre o esforço fiscal necessário para estabilizar a proporção Dívida/PIB.

\subsection{Modelo Analítico}

O ponto de partida para a análise do saldo primário do governo consiste em estabelecer uma trajetória capaz de identificar se o setor público conseguirá honrar os compromissos financeiros assumidos. Com isso, podemos avaliar a trajetória do saldo primário do governo compatível com a sustentabilidade da dívida pública.

Com base no modelo proposto por Hermann (2004), podemos assumir a seguinte identidade contábil:

$$
G_{t}=T_{t}+N B_{t}
$$

onde $G_{t}$ representa os gastos totais, $T_{t}$ é a receita de impostos e $N B_{t}$ é a emissão de novos títulos pelo governo.

Sabe-se que

$$
G_{t}=G P_{t}+G F_{t}
$$

A equação (2) representa todos os gastos ou dispêndios do governo, como compras de bens e serviços, transferências, investimentos, pagamento de juros etc. A equação decompõe esses gastos totais $\left(G_{t}\right)$ em gastos primários $\left(G P_{t}\right)$ e despesas financeiras do governo $\left(G F_{t}\right)$.

Iremos nos preocupar agora com o último termo do lado direito da equação (2), $G F_{t}$.

$$
G F_{t}=A_{t}+J_{t}
$$

onde, 
$A_{t}=$ amortizações da dívida pública em títulos $\left(B_{t-1}\right): A_{t}=a_{t} B_{t-1}$;

$a_{t}=$ percentual da dívida pública do período $t-l$ que será amortizada no período $t$.

$J_{t}=$ despesas com juros sobre $B_{t-1}: J_{t}=r_{t} B_{t-1}$;

$r_{t}=$ taxa de remuneração nominal dos títulos da dívida pública.

Portanto:

$$
G F_{t}=\left(a_{t}+r_{t}\right) B_{t-1}
$$

Da equação (1), decompondo $N B_{t}$, teremos:

$$
N B_{t}=N B m_{t}+N B b c_{t}
$$

onde,

$N B m_{t}=$ títulos adquiridos pelo mercado;

$N B b c_{t}=$ títulos adquiridos pelo Banco Central $=\Delta H_{t}=$ variação da base monetária.

Igualando (1) e (2), fazendo as devidas alterações, obtemos:

$$
G P_{t}+A_{t}+J_{t}=T_{t}+N B m_{t}+\Delta H_{t}
$$

Trabalhando com os dois lados dessa última identidade:

$$
G P_{t}+J_{t}-T_{t}=N B m_{t}-A_{t}+\Delta H_{t}
$$

Como $\left(N B m_{t}-A_{t}\right)$ é a variação líquida no estoque da dívida pública em títulos, a equação (7) pode ser transformada em

$$
s p_{t}=\Delta B_{t}-J_{t}+\Delta H_{t}
$$

Aqui, $s p_{t}$ representa o saldo primário do governo $\left(G P_{t}-T_{t}\right), \Delta B_{t}$ é a variação líquida no estoque da dívida pública em títulos e $\Delta H_{t}$ é a variação da base monetária. Para observar a trajetória de $s p_{t}$ ao longo do tempo, iremos utilizar a idéia proposta por Edwards (2003), onde se assume que os agentes internos e externos possuem 
diferentes taxas de acumulação dos títulos da dívida pública. Para isso, iremos reescrever (8) da seguinte forma:

$$
s p_{t}=B_{t}-B_{t-1}-r_{t} B_{t-1}+d H_{t}
$$

onde,

$$
\begin{aligned}
& B_{t}-B_{t-1}=\Delta B_{t}=\Delta B I_{t}+\Delta B E_{t} \\
& r_{t} B_{t-1}=r_{t} B I_{t-1}+r_{t} B E_{t-1}
\end{aligned}
$$

$\Delta B I_{t}$ e $\Delta B E_{t}$ representam, respectivamente, as variações das dívidas interna e externa. A soma dessas variaçóes representa a variação líquida no estoque da dívida pública em títulos. Assumindo que $\Delta B I_{t}$ e $\Delta B E_{t}$ se comportam de acordo com uma taxa de acumulação dos títulos da dívida dos agentes internos e externos, respectivamente, obtemos:

$$
s p_{t}=\theta\left(B I_{t-1}\right)-r_{t} B I_{t-1}+\beta\left(B E_{t-1}\right)-r_{t} B E_{t-1}+\Delta H_{t}
$$

onde,

$$
\begin{aligned}
& \Delta B I_{t}=\theta\left(B I_{t-1}\right) \\
& \Delta B E_{t}=\beta\left(B E_{t-1}\right)
\end{aligned}
$$

Dividindo cada termo da identidade (11) pelo PIB nominal, teremos:

$$
\frac{s p_{t}}{Y_{t}}=\left(\theta-r_{t}\right) \frac{B I_{t-1}}{Y_{t}}+\left(\beta-r_{t}\right) \frac{B E_{t-1}}{Y_{t}}+\frac{\Delta H_{t}}{Y_{t}}
$$

Esta equação mostra que o superávit primário atual do governo, como proporção do PIB, depende do estoque dos dois tipos de dívida, interna e externa, de sua variação entre os períodos $t$ e $t-1$, da taxa que remunera os títulos da dívida e da razão senhoriagem/PIB.

A partir da equação (12), pode-se derivar outra que será a base para as projeções do saldo primário do governo necessário para manter a dívida pública estável. Em uma primeira etapa, a equação que se quer é semelhante a (12), exceto que se arranjam os termos de modo a definir tanto a dívida interna quanto a externa, no período 
$t-1$, como igual à diferença entre a dívida no período $t$ e a dívida no período zero, assim como o PIB nominal no período $t$ como igual à soma do PIB nominal entre o período $t-1$ e o período zero.

Agora, em uma segunda etapa, usa-se a equação (12) para achar o valor de $\frac{s p_{t+1}}{Y_{t+1}}$, substituindo $t$ por $t+1$; e do mesmo modo, acham-se os valores de $\frac{s p}{Y}$ para os períodos seguintes, obtendo assim $\frac{s p_{t}}{Y_{t}}$ como o valor presente da sucessão de saldos primários do governo que se quer projetar, considerando $t$ períodos à frente do período atual, que nesse caso será o período zero. Em uma terceira etapa, transformase o crescimento discreto da equação (12) em uma versão contínua equivalente, utilizando a base $e$, de uma função exponencial natural. Feitas essas alterações, a equação (12) pode ser reescrita da seguinte forma:

$$
\frac{s p_{t}}{Y_{t}}=\left[\left\{\theta-r_{t}\right\}\left(\frac{B I_{0}}{Y_{0}}\right) e^{(\theta-g-\pi)(t-1)}+\left\{\beta-r_{t}\right\}\left(\frac{B E_{0}}{Y_{0}}\right) e^{(\beta-g-\pi)(t-1)}\right]\left[\frac{1}{(1+g+\pi)}\right]+\left(g+\pi^{*}\right)\left(\frac{H_{0}}{Y_{0}}\right)
$$

Esta equação, tal como exposta por Edwards (2003), e aqui utilizada para projeções do saldo primário do governo, pode ser considerada uma versão da restrição orçamentária intertemporal. Ela indica que o valor presente do saldo primário do governo como proporção do PIB, que atende à restrição orçamentária, depende das seguintes variáveis:

$(g+\pi)=$ taxa de crescimento nominal do PIB, composta pela sua taxa real de crescimento $g$ mais a inflação verificada no período, $\pi$;

$\theta=$ taxa de acumulação à qual os agentes internos desejam adquirir títulos da dívida pública - demanda por títulos da dívida pública dos residentes no país;

$\beta=$ taxa de acumulação à qual os agentes externos desejam adquirir títulos da dívida pública - demanda por títulos da dívida pública dos não residentes no país;

$r=$ taxa de juro real para ambos os tipos da dívida, interna e externa; ${ }^{3}$

$\frac{B I_{0}}{Y_{0}}=$ relação inicial do valor de face da Dívida Pública Interna como proporção do PIB;

3 Será assumida a hipótese de perfeita substituição entre títulos internacionais e domésticos, justificada pela arbitragem entre os títulos que ocorre no mercado secundário. 
$\frac{B E_{0}}{Y_{0}}=$ relação inicial do valor de face da Dívida Pública Externa como proporção do PIB;

$\pi^{*}=$ meta de inflação projetada para o período $t$;

$\frac{H_{0}}{Y_{0}}=$ relação inicial da Base Monetária pelo PIB.

A partir dos valores de $\frac{B I_{0}}{Y_{0}}$ e $\frac{B E_{0}}{Y_{0}}$, a trajetória do saldo primário do governo dependerá da taxa de juros para ambos os tipos de dívida, das taxas de inflação observada e projetada pelo Banco Central, da taxa de crescimento do PIB real e da demanda pelos títulos, $\theta$ e $\beta$.

No que se refere à evolução do saldo primário do governo como proporção do PIB no tempo - $\left(\frac{s p_{t}}{Y_{t}}\right)$ - iremos considerar, tal como desenvolvido por Edwards (2003), quatro suposições com relação ao valor de $\theta$, porém, iremos assumir também essas quatro suposições para $\beta$. Estas suposições vão desde uma percepção de risco pessimista, em que os agentes não desejam acumular títulos públicos, até uma percepção de risco otimista na qual a acumulação de títulos públicos é igual à taxa de crescimento do produto. De maneira mais específica, iremos simular a trajetória do saldo primário como proporção do PIB tendo em vista os cenários e percepções de riscos de acordo com o Quadro 1, de modo que iremos associar a percepção de risco com a demanda por títulos públicos, ou seja, quanto mais otimista maior a demanda pelo mesmo.

Com base no Quadro l, as simulações serão feitas considerando inicialmente três tipos de Ambientes:

- no Cenário I, iremos supor heterogeneidade na demanda por títulos públicos no mercado interno e externo, de modo que $\theta$ assume sempre o valor do crescimento nominal do PIB $-\theta=g+\pi$, e $\beta$ assume diferentes valores considerando a percepção de risco, como definido no Quadro l; 
- para o Cenário II, também consideramos heterogeneidade nas taxas de acumulação de títulos da dívida interna e externa, assumindo diferentes demandas para os títulos da Dívida Interna e $\beta=g+\pi$;

- no Cenário III, é considerado valor idêntico para as taxas de acumulação dos títulos da dívida interna e externa.

A idéia com a utilização de diferentes taxas de acumulação dos títulos públicos é mostrar a importância do grau de liquidez no mercado de títulos públicos. Entendese que um ativo é líquido quando houver uma expectativa de demanda suficiente para absorver novas colocações sem que os preços dos papéis tenham de cair demais para atrair compradores, ou seja, liquidez nada mais é do que a expectativa de demanda firme pelo ativo. Existirão compradores para os títulos se houver agentes convencidos de que o desempenho dos papéis será positivo no futuro. Portanto, quanto maior for a taxa de acumulação dos títulos, mais otimistas estarão os agentes e maior será a demanda pelos títulos públicos. 
QUADRO I - DIFERENTES CENÁRIOS E DEMANDAS PELOS TÍTULOS PÚBLICOS PARA A TRAJETÓRIA DO SALDO PRIMÁRIO DO GOVERNO COMPATÍVEL COM A ESTABILIDADE DA PROPORÇÃO DÍVIDA/PIB

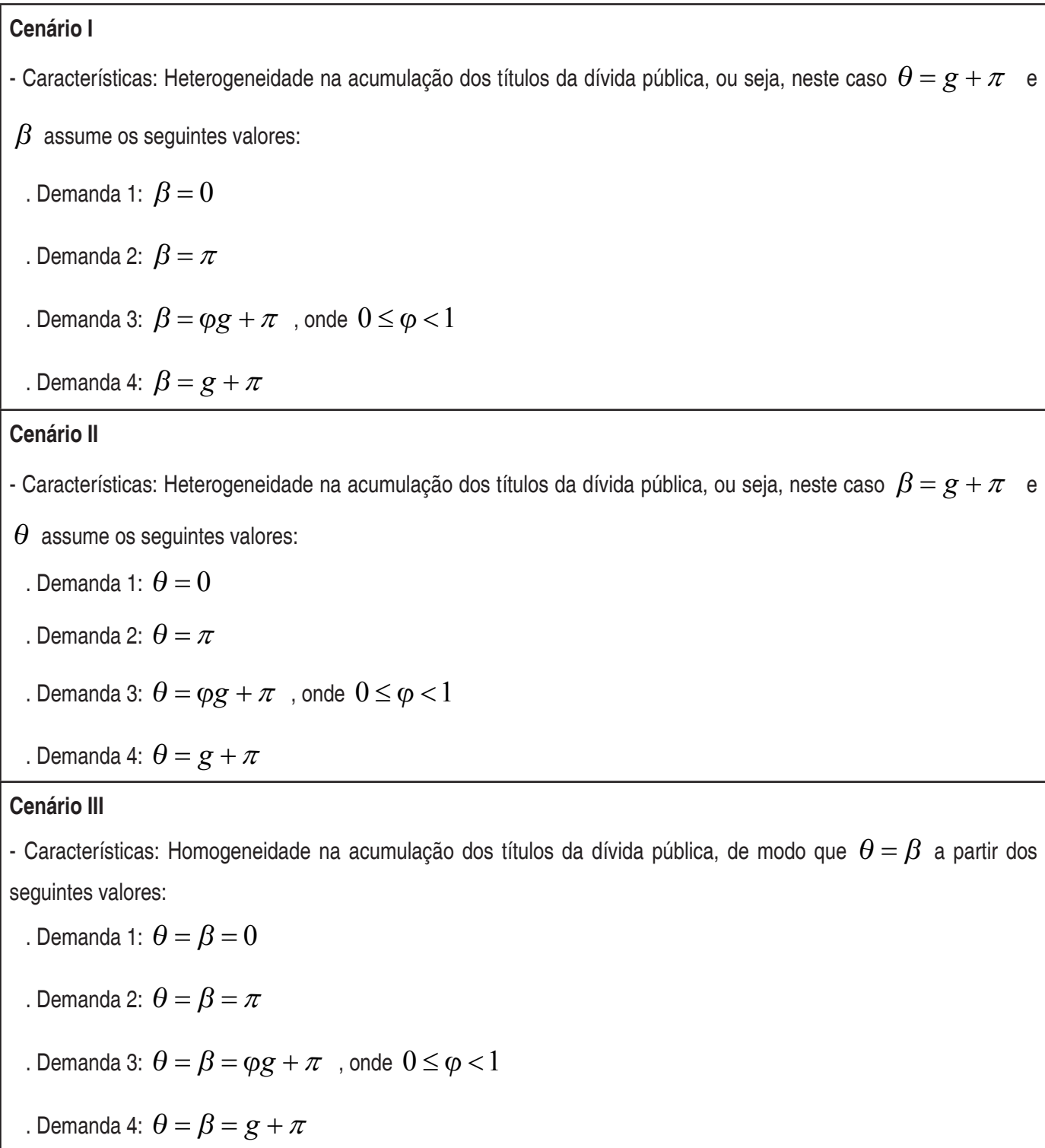

Nota: Assumimos que $\varphi=0,5 \mathrm{em}$ todos os cenários. 


\section{RESULTADO DAS SIMULAÇÕES}

Na simulação da trajetória do superávit primário que estabiliza a relação dívida/PIB foram considerados valores iniciais dos parâmetros compatíveis com o início do regime de metas de inflação no Brasil. Os cenários com diferentes taxas de acumulação de títulos são estendidos por variações em três variáveis macroeconômicas que influenciam os resultados: taxa de crescimento do PIB, meta de inflação do banco central e rentabilidade real dos títulos públicos.

O Quadro 2 mostra os valores dos parâmetros utilizados para simular a trajetória do saldo primário do governo, de acordo com a equação (13).

QUADRO 2 - VALORES DOS PARA AMETROS USADOS NAS SIMULAÇÕES DA TRAJETÓRIA DO SALDO PRIMÁRIO DO GOVERNO COMPATÍVEL COM A ESTABILIDADE DA RELAÇÃO DÍVIDA/PIB

\begin{tabular}{|c|c|c|c|}
\hline Parâmetros & Símbolo & Valor assumido & Comentários \\
\hline $\begin{array}{l}\text { Dívida Interna como proporção } \\
\text { do PIB }\end{array}$ & $\frac{B I_{0}}{Y_{0}}$ & $39,0 \%$ & Valor verificado no ano de 1999 \\
\hline $\begin{array}{l}\text { Dívida Externa como proporção } \\
\text { do PIB }\end{array}$ & $\frac{B E_{0}}{Y_{0}}$ & $10,4 \%$ & Valor verificado no ano de 1999 \\
\hline $\begin{array}{l}\text { Demanda dos agentes internos } \\
\text { pelos Títulos da Dívida Pública }\end{array}$ & $\theta$ & $\begin{array}{l}\text { Diferentes suposições de } \\
\text { acordo com o Quadro } 1\end{array}$ & - \\
\hline $\begin{array}{l}\text { Demanda dos agentes externos } \\
\text { pelos Títulos da Dívida Pública }\end{array}$ & $\beta$ & $\begin{array}{l}\text { Diferentes suposições de } \\
\text { acordo com o Quadro } 1\end{array}$ & - \\
\hline Taxa de crescimento real do PIB & $g$ & $2 \%$ & $\begin{array}{l}\text { Média da Taxa de crescimento do } \\
\text { PIB no período 1999-2003 }\end{array}$ \\
\hline Meta de Inflação & $\pi^{*}$ & $8,0 \%$ & $\begin{array}{c}\text { Meta de Inflação projetada para } \\
1999 .\end{array}$ \\
\hline Inflação verificada no período & $\pi$ & $8,9 \%$ & $\begin{array}{c}\text { Inflação verificada no ano de } 1999, \\
\text { medida pelo IPCA }\end{array}$ \\
\hline $\begin{array}{l}\text { Taxa de remuneração dos } \\
\text { Títulos da Dívida Pública }\end{array}$ & $r$ & $18,8 \%$ & Taxa Selic no ano de 1999. \\
\hline $\begin{array}{l}\text { Base Monetária como proporção } \\
\text { do PIB }\end{array}$ & $\frac{H_{0}}{Y_{0}}$ & $4,6 \%$ & Valor verificado em 1999 \\
\hline
\end{tabular}




\subsection{Mudanças na Taxa de Crescimento Real do PIB}

No que se refere ao comportamento da trajetória da proporção saldo primário do governo/PIB, levando em conta diferentes valores para a taxa de crescimento real do $\mathrm{PIB}$, os principais resultados, mostrados na Tabela $\mathrm{l}$ e Gráficos la, lb e lc, são:

- o saldo primário do governo é sensível a mudanças na taxa de crescimento real do PIB, independente do cenário e demanda por títulos públicos considerados, de modo que quanto maior essa taxa, menor é o esforço fiscal necessário para manter a sustentabilidade da dívida pública;

- com exceção dos casos das demandas 2 e 3, associado a uma queda no PIB real, a trajetória do saldo primário do governo exibe um menor esforço fiscal no decorrer do tempo;

- quanto maior a propensão de acumulação dos títulos da dívida pública por parte dos agentes internos, mantida constante a taxa de acumulação dos títulos da dívida pública por parte dos agentes externos, menor é o esforço fiscal ao longo do tempo necessário para manter a sustentabilidade da dívida, exceção feita para a taxa de crescimento real do PIB negativa.

Assumindo um cenário de heterogeneidade na taxa de acumulação dos títulos públicos (Cenário I), o aumento na demanda por parte dos agentes externos faz com que a demanda pelos títulos passe de Demanda 1 para Demanda 2 no Gráfico la. A elevação do valor de $\beta$ de zero para $\pi$ provoca o deslocamento para baixo da curva que relaciona o saldo primário e a taxa de crescimento real do PIB, o que significa um esforço físcal menor. Se a taxa de acumulação dos títulos da dívida pública aumentar, a declividade desta curva aumenta com o valor de $\beta$. Essa análise produz um resultado interessante: quanto maior a demanda pelos títulos da dívida pública, mais sensível a alteraçôes na taxa de crescimento real do PIB será o resultado primário necessário para estabilizar a proporção dívida/PIB. Este resultado é intuitivo, na medida em que uma expansão da demanda pelos títulos provoca um efeito indireto sobre o crescimento do PIB. Uma demanda maior pelos papéis eleva os seus preços, ou seja, uma redução nas taxas de juros, o que estimula a atividade econômica. 
TABELA I - TRAJETÓRIA DO SALDO PRIMÁRIO DO GOVERNO (\%PIB) NECESSÁRIO PARA A ESTABILIDADE DA PROPORÇÃO DÍVIDA/ PIB SOB CENÁRIOS E DEMANDAS PELOS TÍTULOS DA DÍVIDA PÚBLICA ALTERNATIVOS CONSIDERANDO DIFERENTES TAXAS DE CRESCIMENTO REAL DO PIB

\begin{tabular}{|c|c|c|c|c|c|c|c|c|c|}
\hline \multirow{3}{*}{$\begin{array}{l}\text { Tempo } \\
\text { (anos) }\end{array}$} & \multicolumn{3}{|c|}{ Cenário I } & \multicolumn{3}{|c|}{ Cenário II } & \multicolumn{3}{|c|}{ Cenário III } \\
\hline & \multicolumn{3}{|c|}{ Var. do PIB } & \multicolumn{3}{|c|}{ Var. do PIB } & \multicolumn{3}{|c|}{ Var. do PIB } \\
\hline & $-1 \%$ & $2 \%$ & $5 \%$ & $-1 \%$ & $2 \%$ & $5 \%$ & $-1 \%$ & $2 \%$ & $5 \%$ \\
\hline \multicolumn{10}{|c|}{ Demanda 1} \\
\hline 1 & 6,73 & 6,12 & 5,53 & 4,97 & 3,76 & 2,60 & 7,49 & 7,14 & 6,80 \\
\hline 5 & 5,10 & 4,06 & 3,11 & 4,48 & 3,14 & 1,87 & 5,37 & 4,45 & 3,65 \\
\hline 10 & 3,68 & 2,47 & 1,48 & 4,05 & 2,66 & 1,38 & 3,52 & 2,39 & 1,52 \\
\hline \multicolumn{10}{|c|}{ Demanda 2} \\
\hline 1 & 3,89 & 3,36 & 2,85 & 4,11 & 2,93 & 1,79 & 3,80 & 3,55 & 3,30 \\
\hline 5 & 4,02 & 3,12 & 2,30 & 4,15 & 2,85 & 1,63 & 3,96 & 3,24 & 2,60 \\
\hline 10 & 4,19 & 2,85 & 1,76 & 4,20 & 2,77 & 1,46 & 4,18 & 2,89 & 1,89 \\
\hline \multicolumn{10}{|c|}{ Demanda 3} \\
\hline 1 & 4,05 & 3,05 & 2,09 & 4,16 & 2,83 & 1,56 & 4,00 & 3,14 & 2,32 \\
\hline 5 & 4,12 & 2,94 & 1,88 & 4,18 & 2,80 & 1,50 & 4,09 & 3,00 & 2,04 \\
\hline 10 & 4,20 & 2,81 & 1,64 & 4,21 & 2,76 & 1,43 & 4,20 & 2,83 & 1,73 \\
\hline \multicolumn{10}{|c|}{ Demanda 4} \\
\hline 1 & 4,21 & 2,74 & 1,34 & 4,21 & 2,74 & 1,34 & 4,21 & 2,74 & 1,34 \\
\hline 5 & 4,21 & 2,74 & 1,34 & 4,21 & 2,74 & 1,34 & 4,21 & 2,74 & 1,34 \\
\hline 10 & 4,21 & 2,74 & 1,34 & 4,21 & 2,74 & 1,34 & 4,21 & 2,74 & 1,34 \\
\hline
\end{tabular}

Fonte: Elaboração própria a partir da equação 13.

Mantida a heterogeneidade na taxa de acumulação de títulos, mas alterando os valores de $\theta$ (acumulação interna) e mantendo $\beta$ como $g+\pi$, o resultado é o mesmo, como pode ser visto no Quadro 1.

No terceiro caso, assumindo homogeneidade na taxa de acumulação dos títulos públicos, Cenário III, de modo que $\beta$ e $\theta$ assumem valores idênticos nos quatro tipos de demanda pelos papéis definidos de acordo com o Quadro 1, os resultados mostraram-se idênticos aos encontrados nos Cenários I e II, como pode ser visto no Gráfico lc. 
GRÁFICO I - SALDO PRIMÁRIO DO GOVERNO NECESSÁRIO PARA A ESTABILIDADE DA PROPORÇÃO DÍVIDA/PIB E TAXA DE CRESCIMENTO DO PIB REAL SOB CENÁRIOS E DEMANDAS PELOS TÍTULOS PÚBLICOS ALTERNATIVOS

GRÁFICO IA-CENÁRIO I

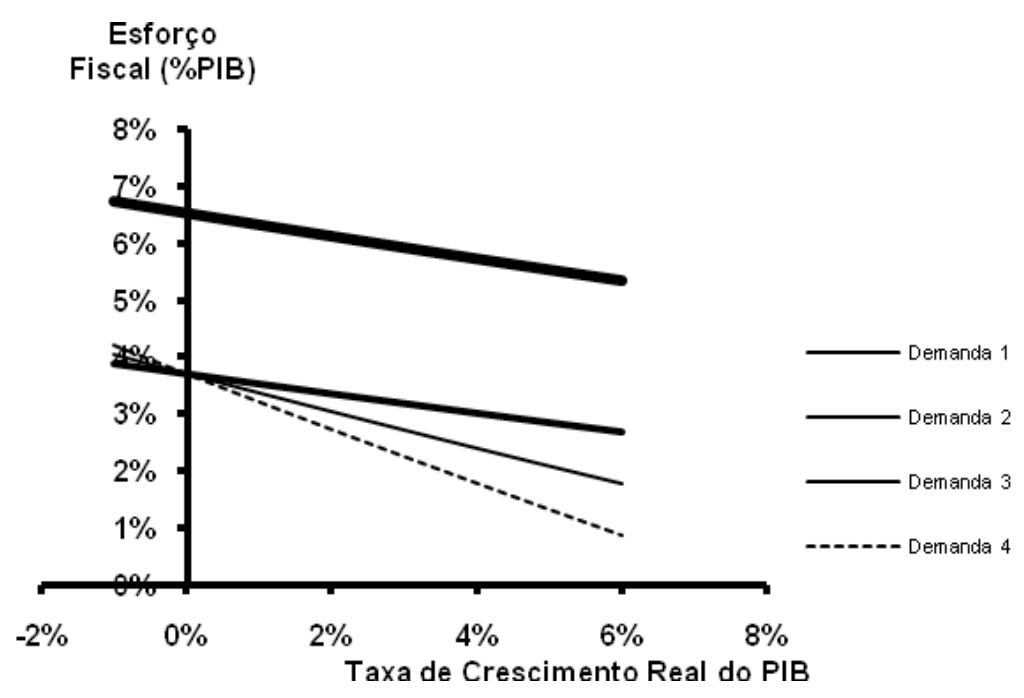

GRÁFICO IB-CENÁRIO 2

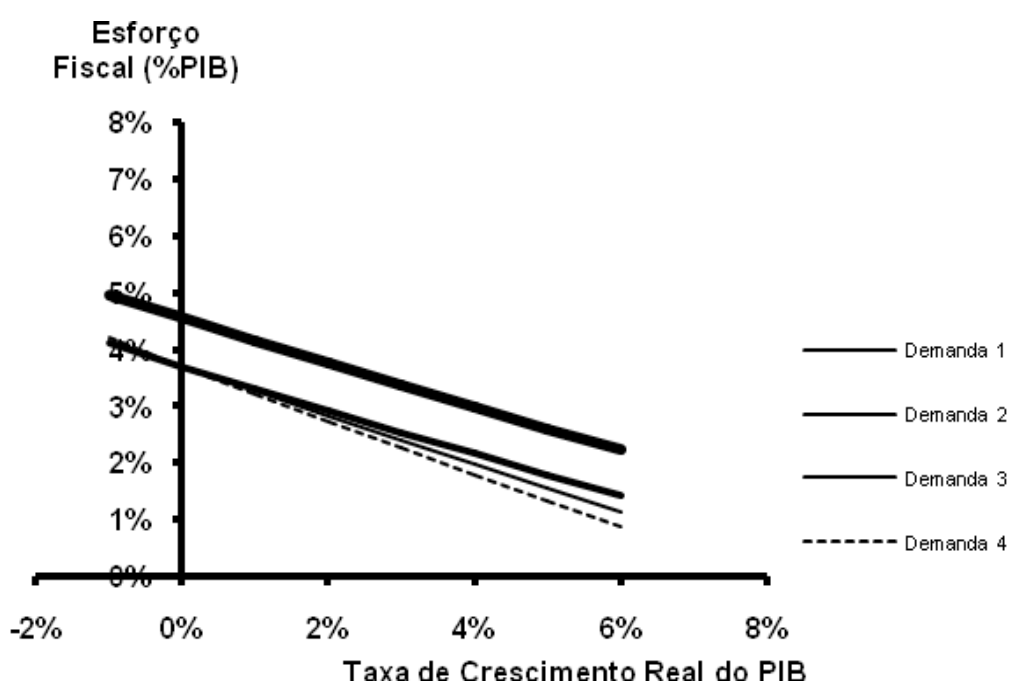




\section{GRÁFICO IC - CENÁRIO 3}

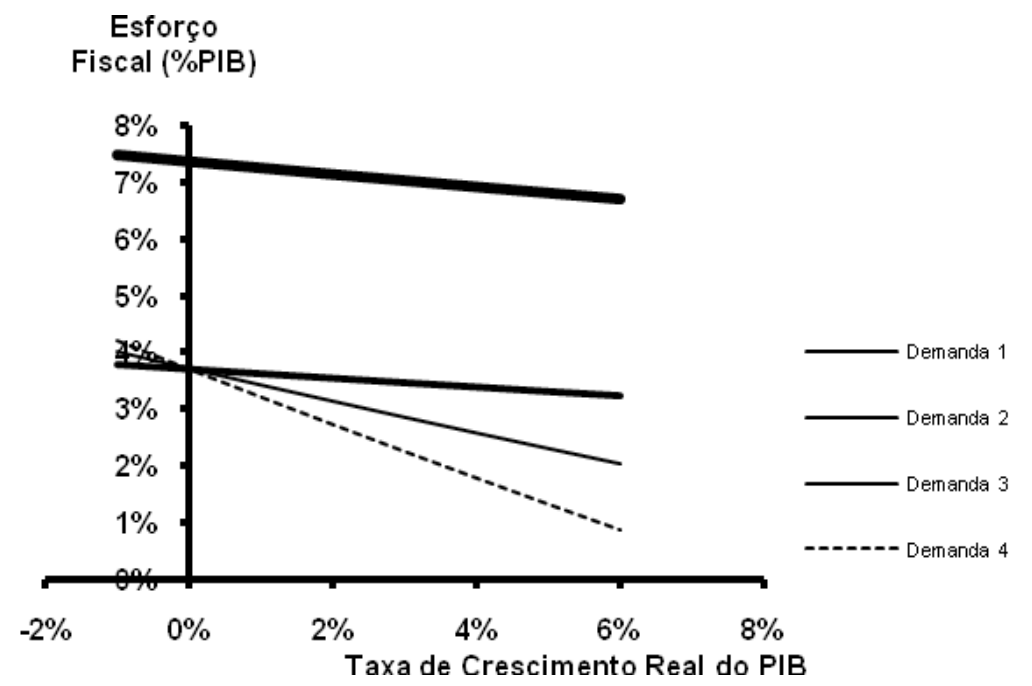

\subsection{Mudanças na Taxa de Inflação Perseguida pelo Banco Central}

Mantendo tudo o mais constante, inclusive a taxa de crescimento real do PIB ao nível de $2 \%$ e com diferentes valores para a meta de inflação a ser perseguida pelo Banco Central, os principais resultados, mostrados na Tabela 2 e Gráficos 2a, $2 \mathrm{~b}$ e 2c, são:

- para todos os cenários a trajetória do saldo primário é de redução do esforço fiscal;

- quanto menor a propensão de acumulação dos títulos, maior deverá ser o esforço fiscal.

Para todos os cenários, os resultados mostraram que alterações na demanda por títulos públicos (taxa de acumulação dos papéis) não provocam mudanças na sensibilidade do saldo primário do governo em relação à meta de inflação. Ao contrário do que ocorreu na análise entre o saldo primário do governo e a taxa de crescimento real do PIB, alterações na demanda pelos títulos públicos geraram apenas deslocamentos paralelos da curva que relaciona $\left(\frac{s p_{t}}{Y_{t}}, \pi^{*}\right)$. Apesar de a sensibilidade do saldo primário do governo em relação à meta de inflação perseguida pelo Banco Central não se alterar com a demanda pelos títulos da dívida pública, quanto maior 
essa demanda, menor será o esforço fisscal para manter constante a dívida pública como proporção do PIB.

TABELA 2 - TRAJETÓRIA DO SALDO PRIMÁRIO (\%PIB) DO GOVERNO NECESSÁRIO PARA A ESTABILIDADE DA PROPORÇÃO DÍVIDA/ PIB SOB CENÁRIOS E DEMANDAS PELOS TÍTULOS DA DÍVIDA PÚBLICA ALTERNATIVOS CONSIDERANDO DIFERENTES TAXAS PARA A META DE INFLAÇÃO

\begin{tabular}{|c|c|c|c|c|c|c|c|c|c|}
\hline \multirow{3}{*}{ Tempo } & \multicolumn{3}{|c|}{ Cenário I } & \multicolumn{3}{|c|}{ Cenário II } & \multicolumn{3}{|c|}{ Cenário III } \\
\hline & \multicolumn{3}{|c|}{ Meta de Inflação } & \multicolumn{3}{|c|}{ Meta de Inflação } & \multicolumn{3}{|c|}{ Meta de Inflação } \\
\hline & $10 \%$ & $7 \%$ & $3 \%$ & $10 \%$ & $7 \%$ & $3 \%$ & $10 \%$ & $7 \%$ & $3 \%$ \\
\hline \multicolumn{10}{|c|}{ Demanda 1} \\
\hline 1 & 6,03 & 6,16 & 6,35 & 3,67 & 3,81 & 3,99 & 7,05 & 7,19 & 7,37 \\
\hline 5 & 3,96 & 4,10 & 4,29 & 3,04 & 3,18 & 3,37 & 4,36 & 4,50 & 4,68 \\
\hline 10 & 2,38 & 2,52 & 2,70 & 2,57 & 2,70 & 2,89 & 2,30 & 2,44 & 2,62 \\
\hline \multicolumn{10}{|c|}{ Demanda 2} \\
\hline 1 & 3,27 & 3,40 & 3,59 & 2,83 & 2,97 & 3,16 & 3,45 & 3,59 & 3,78 \\
\hline 5 & 3,03 & 3,17 & 3,35 & 2,76 & 2,90 & 3,08 & 3,15 & 3,28 & 3,47 \\
\hline 10 & 2,76 & 2,90 & 3,08 & 2,68 & 2,82 & 3,00 & 2,79 & 2,93 & 3,12 \\
\hline \multicolumn{10}{|c|}{ Demanda 3} \\
\hline 1 & 2,96 & 3,09 & 3,28 & 2,74 & 2,88 & 3,06 & 3,05 & 3,19 & 3,37 \\
\hline 5 & 2,85 & 2,99 & 3,17 & 2,71 & 2,84 & 3,03 & 2,91 & 3,05 & 3,23 \\
\hline 10 & 272 & 2,86 & 3,04 & 2,67 & 2,81 & 2,99 & 2,74 & 2,88 & 3,06 \\
\hline \multicolumn{10}{|c|}{ Demanda 4} \\
\hline 1 & 2,65 & 2,78 & 2,97 & 2,65 & 2,78 & 2,97 & 2,65 & 2,78 & 2,97 \\
\hline 5 & 2,65 & 2,78 & 2,97 & 2,65 & 2,78 & 2,97 & 2,65 & 2,78 & 2,97 \\
\hline 10 & 2,65 & 2,78 & 2,97 & 2,65 & 2,78 & 2,97 & 2,65 & 2,78 & 2,97 \\
\hline
\end{tabular}

Fonte: Elaboração própria a partir da equação 13. 
GRÁFICO 2 - SALDO PRIMÁRIO DO GOVERNO NECESSÁRIO PARA A ESTABILIDADE DA PROPORÇÃO DÍVIDA/PIB E TAXA DE INFLAÇÃO PERSEGUIDA PELO BANCO CENTRAL SOB CENÁRIOS E DEMANDAS PELOS TÍTULOS PÚBLICOS ALTERNATIVOS

GRÁFICO 2A-CENÁRIO I

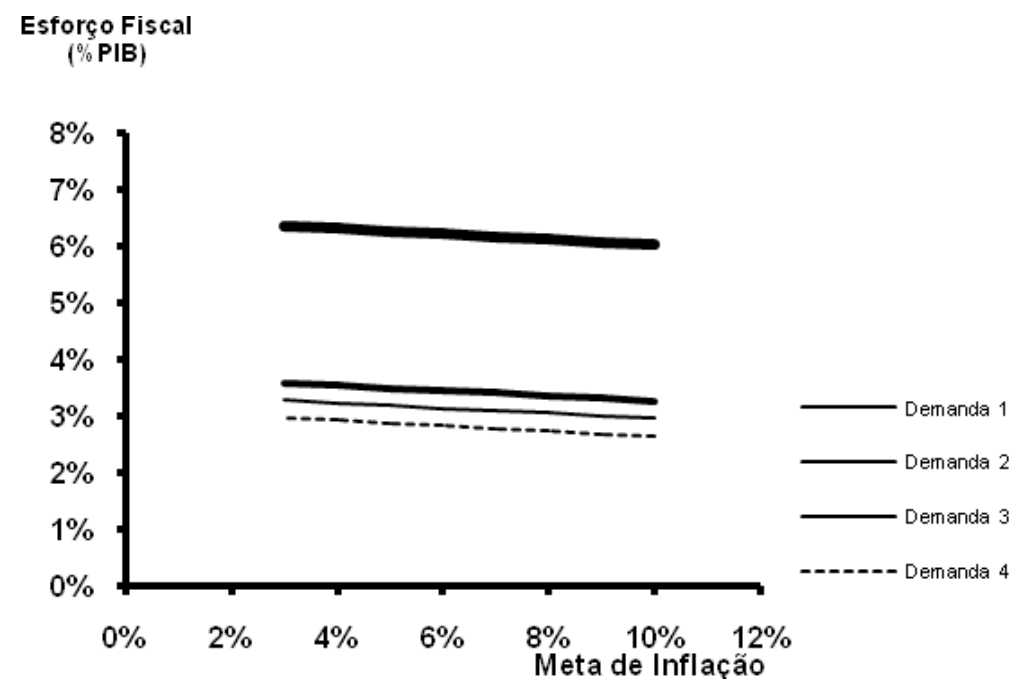

GRÁFICO 2B-CENÁRIO 2

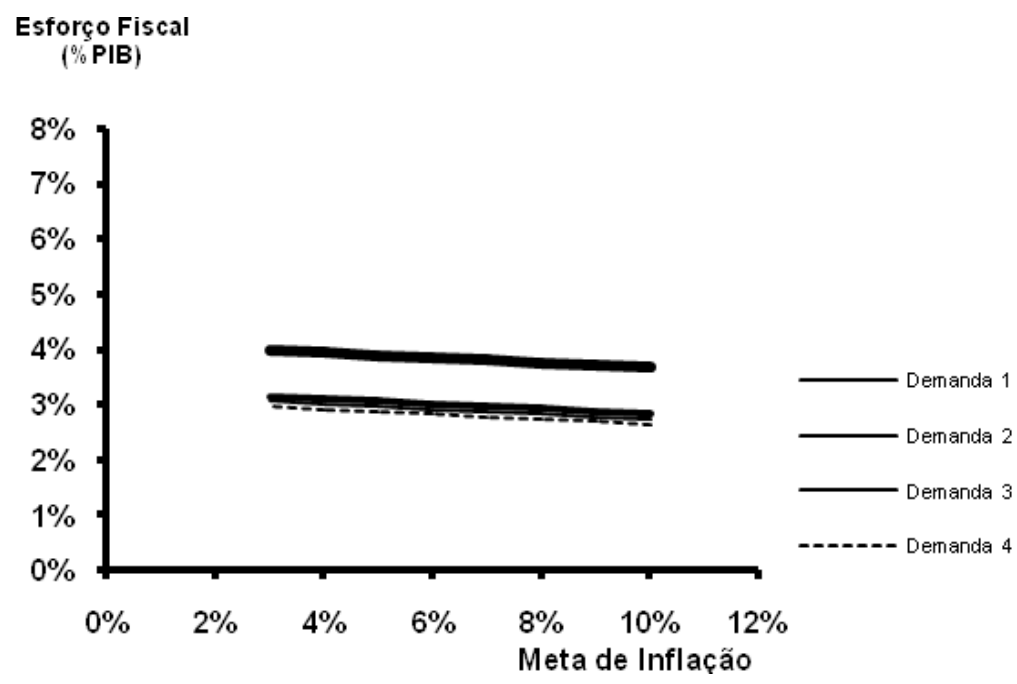




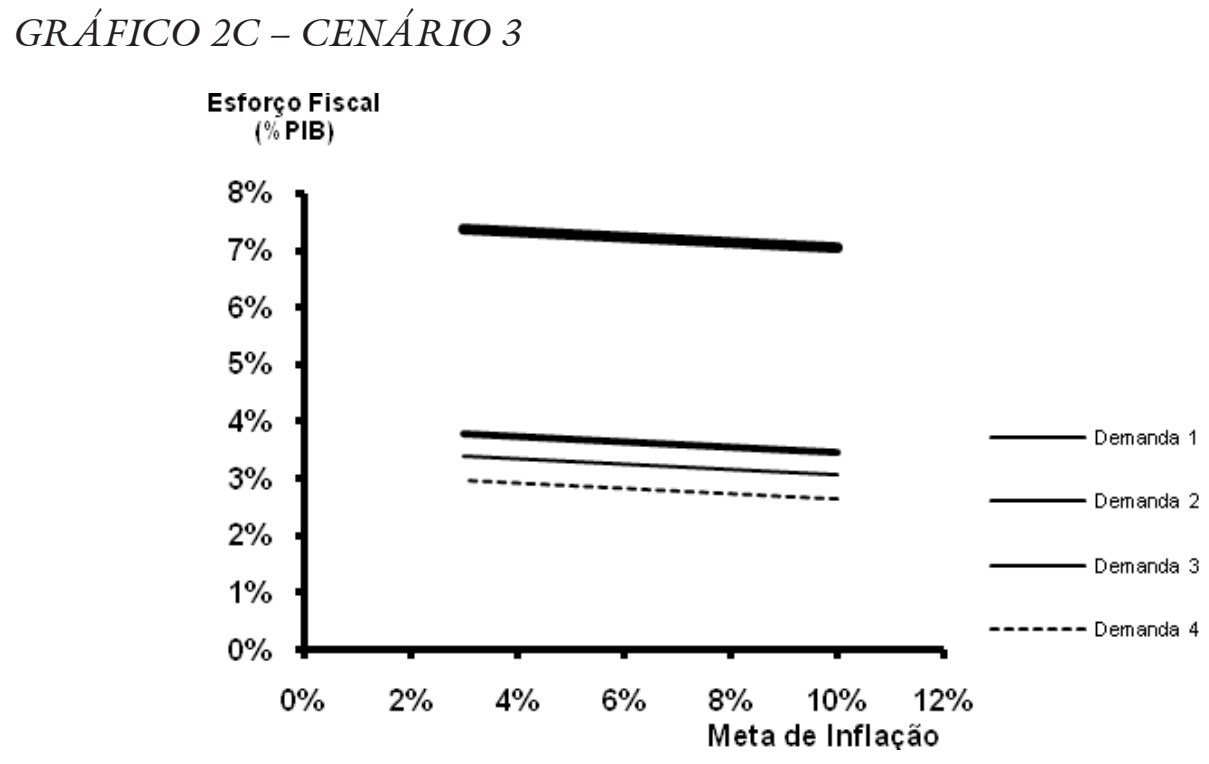

\subsection{Alterações na Taxa de Remuneração dos Titulos da Dívida Pública}

Alterações na remuneração dos títulos da dívida pública geraram como principais resultados sobre a trajetória do saldo primário, conforme Tabela 3 e Gráficos 3a, $3 b$ e $3 c$ :

- mudanças na remuneração dos títulos da dívida pública geram mudanças no esforço fiscal, de modo que quanto menor a taxa de remuneração dos títulos públicos, menor precisará ser o superávit primário para manter a sustentabilidade da dívida pública;

- para todos os cenários observados a trajetória do saldo primário exibe um menor esforço fiscal ao longo do tempo;

- quanto maior o ritmo de acumulação dos títulos, menor é o esforço fiscal.

Caso ocorra uma expansão na demanda pelos títulos públicos, a uma dada taxa de remuneração, o esforço fiscal requerido será menor quanto maior for a procura pelos títulos, conforme pode ser visto nos Gráficos 3a, 3b e 3c. Uma mudança na taxa de acumulação dos títulos públicos deixa inalterada a sensibilidade do esforço fiscal a uma dada alteração na taxa que remunera tais títulos. A mudança na demanda pelos títulos, como no caso anterior da meta de inflação, irá provocar deslocamentos paralelos da curva no plano $\left(\frac{s p_{t}}{Y_{t}}, r\right)$. 
TABELA 3 - TRAJETÓRIA DO SALDO PRIMÁRIO DO GOVERNO (\%PIB) NECESSÁRIO PARA A ESTABILIDADE DA RELAÇÃO DÍVIDA/ PIB SOB CENÁRIOS E DEMANDAS PELOS TÍTULOS DA DÍVIDA PÚBLICA ALTERNATIVOS CONSIDERANDO DIFERENTES TAXAS DE REMUNERAÇÃO DOS TÍTULOS DA DÍVIDA PÚBLICA

\begin{tabular}{|c|c|c|c|c|c|c|c|c|c|}
\hline \multirow{3}{*}{ Tempo } & \multicolumn{3}{|c|}{ Cenário I } & \multicolumn{3}{|c|}{ Cenário II } & \multicolumn{3}{|c|}{ Cenário III } \\
\hline & \multicolumn{3}{|c|}{$\begin{array}{c}\text { Taxa de remuneração dos Títulos } \\
\text { Públicos }\end{array}$} & \multicolumn{3}{|c|}{$\begin{array}{c}\text { Taxa de remuneração dos Títulos } \\
\text { Públicos }\end{array}$} & \multicolumn{3}{|c|}{$\begin{array}{c}\text { Taxa de remuneração dos } \\
\text { Títulos Públicos }\end{array}$} \\
\hline & $21 \%$ & $17 \%$ & $14 \%$ & $21 \%$ & $17 \%$ & $14 \%$ & $21 \%$ & $17 \%$ & $14 \%$ \\
\hline \multicolumn{10}{|c|}{ Demanda 1} \\
\hline 1 & 7,00 & 5,39 & 4,17 & 4,64 & 3,03 & 1,81 & 8,02 & 6,41 & 5,20 \\
\hline 5 & 4,70 & 3,52 & 2,64 & 3,95 & 2,46 & 1,35 & 5,03 & 3,98 & 3,20 \\
\hline 10 & 2,93 & 2,09 & 1,46 & 3,41 & 2,03 & 0,99 & 2,72 & 2,11 & 1,66 \\
\hline \multicolumn{10}{|c|}{ Demanda 2} \\
\hline 1 & 4,24 & 2,62 & 1,41 & 3,81 & 2,19 & 0,98 & 4,43 & 2,81 & 1,60 \\
\hline 5 & 3,95 & 2,43 & 1,29 & 3,72 & 2,13 & 0,94 & 4,05 & 2,56 & 1,44 \\
\hline 10 & 3,62 & 2,21 & 1,15 & 3,62 & 2,07 & 0,90 & 3,62 & 2,27 & 1,26 \\
\hline \multicolumn{10}{|c|}{ Demanda 3} \\
\hline 1 & 3,93 & 2,31 & 1,10 & 3,71 & 2,10 & 0,89 & 4,02 & 2,41 & 1,20 \\
\hline 5 & 3,80 & 2,23 & 1,05 & 3,67 & 2,07 & 0,87 & 3,85 & 2,30 & 1,13 \\
\hline 10 & 3,63 & 2,12 & 0,99 & 3,62 & 2,04 & 0,85 & 3,64 & 2,16 & 1,05 \\
\hline \multicolumn{10}{|c|}{ Demanda 4} \\
\hline 1 & 3,62 & 2,00 & 0,79 & 3,62 & 2,00 & 0,79 & 3,62 & 2,00 & 0,79 \\
\hline 5 & 3,62 & 2,00 & 0,79 & 3,62 & 2,00 & 0,79 & 3,62 & 2,00 & 0,79 \\
\hline 10 & 3,62 & 2,00 & 0,79 & 3,62 & 2,00 & 0,79 & 3,62 & 2,00 & 0,79 \\
\hline
\end{tabular}

Fonte: Elaboração própria a partir da equação 13. 
GRÁFICO 3 - SALDO PRIMÁRIO DO GOVERNO NECESSÁRIO PARA A ESTABILIDADE DA PROPORÇÃO DÍVIDA/PIB E TAXA DE REMUNERAÇÃO DOS TÍTULOS DA DÍVIDA PÚBLICA SOB CENÁRIOS E DEMANDAS PELOS TÍTULOS PÚBLICOS ALTERNATIVOS

GRÁFICO $3 A-C E N A ́ R I O I$

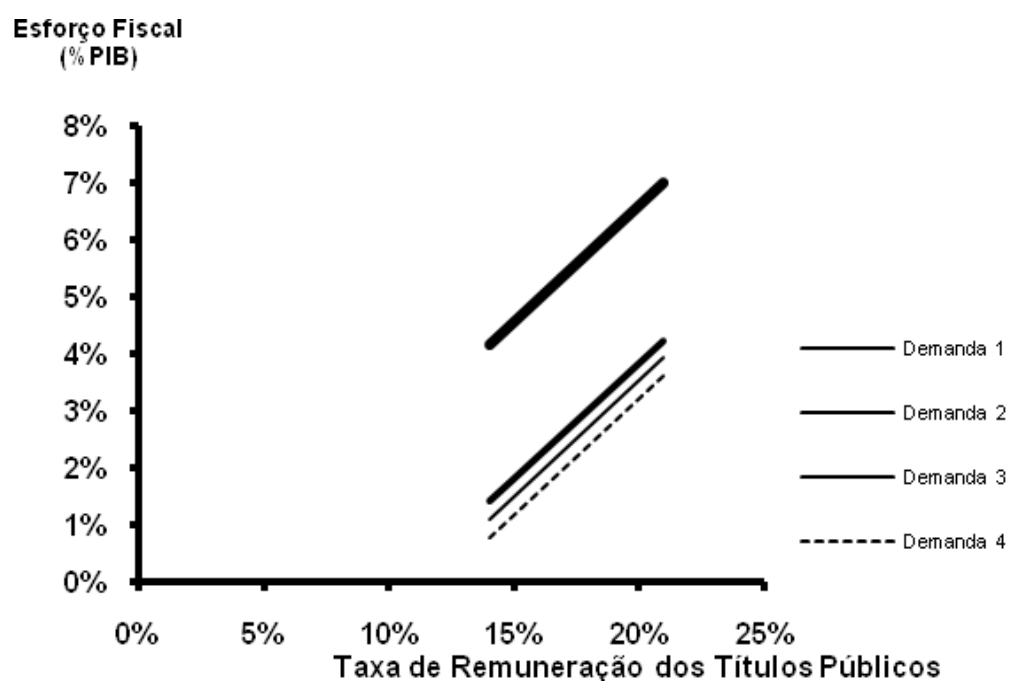

GRÁFICO 3B-CENÁRIO 2

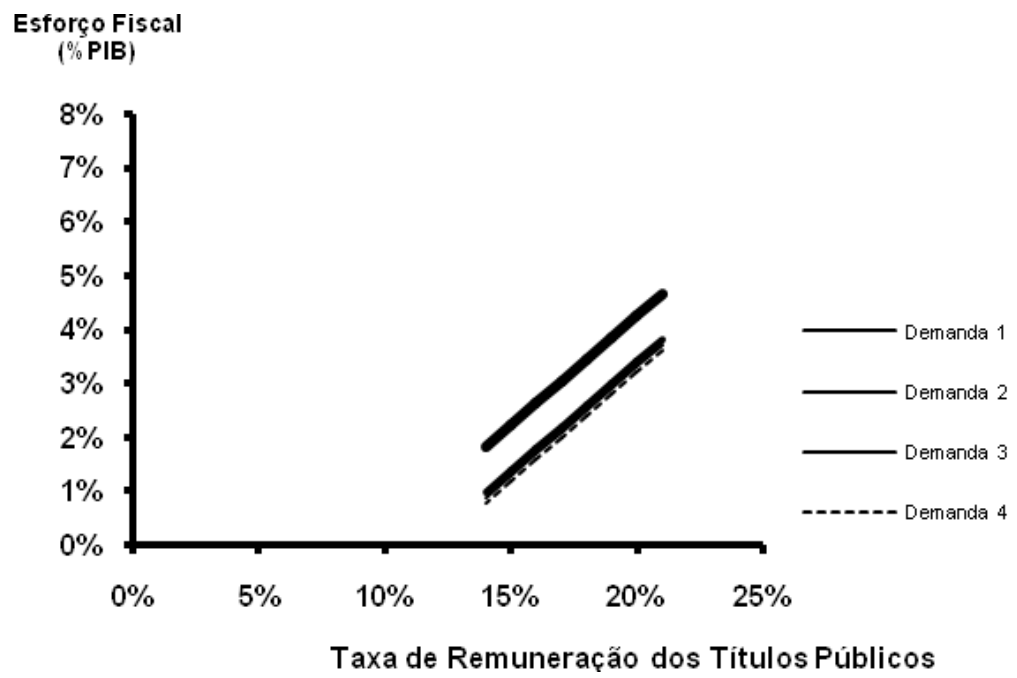




\section{GRÁFICO 3C - CENÁRIO 3}

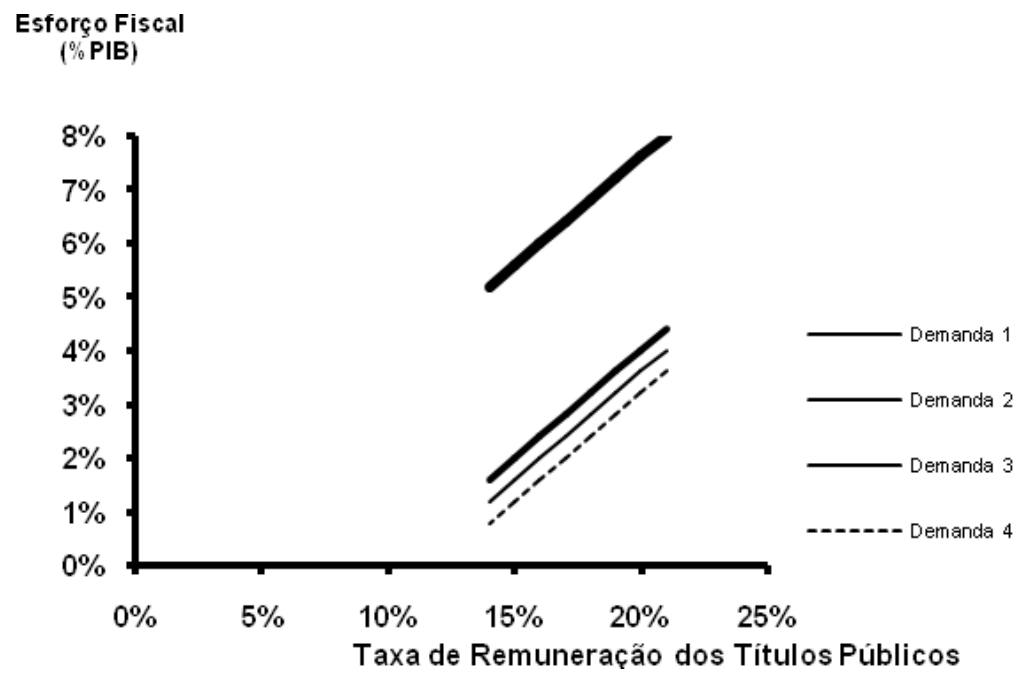

\subsection{Comparação Quantitativa dos Resultados}

A análise desenvolvida até aqui não considerou a magnitude do impacto gerado por alterações na demanda por títulos da dívida pública sobre o esforço fiscal requerido para estabilizar a proporção dívida/PIB para diferentes $g, \pi^{*}$ e $r$. Pela Tabela 4 nota-se que alterações na demanda por tais papéis têm um impacto maior no esforço fiscal no caso de alteração na taxa de crescimento real do PIB comparativamente à meta de inflação perseguida e remuneração dos títulos. As sensibilidades desses dois últimos, como pode ser visto na Tabela 4 , não se alteram com mudanças na taxa de acumulação dos títulos. Como foi observado nos gráficos anteriores, o impacto será o deslocamento das curvas nos planos $\left(\frac{s p_{t}}{Y_{t}}, \pi^{*}\right)$ e $\left(\frac{s p_{t}}{Y_{t}}, r\right)$, deixando inalteradas as sensibilidades. 
TABELA 4 - SENSIBILIDADES DO ESFORÇO FISCAL NECESSÁRIO PARA ESTABILIZAR A PROPORÇÃO DÍVIDA/PIB EM RELAÇÃO A ALGUMAS VARIÁVEIS SELECIONADAS A PARTIR DE DIFERENTES CENÁRIOS E DEMANDAS PELOS TÍTULOS DA DÍVIDA PÚBLICA

\begin{tabular}{cccc}
\hline \multicolumn{5}{c}{ Taxa de crescimento real do PIB } \\
\hline \multicolumn{5}{c}{ Cenário I } & Cenário II & Cenário III \\
\hline Demanda 1 & 0,1978 & 0,3914 & 0,1140 \\
Demanda 2 & 0,1992 & 0,3939 & 0,1218 \\
Demanda 3 & 0,3242 & 0,4296 & 0,2785 \\
Demanda 4 & 0,4752 & 0,4752 & 0,4752 \\
\hline \multicolumn{5}{c}{ Meta de Inflação } \\
\hline Cenário I & Cenário II & Cenário III \\
\hline Demanda 1 & 0,046 & 0,046 & 0,046 \\
Demanda 2 & 0,046 & 0,046 & 0,046 \\
Demanda 3 & 0,046 & 0,046 & 0,046 \\
Demanda 4 & 0,046 & 0,046 & 0,046 \\
\hline & Taxa de remuneração dos Títulos Públicos \\
\hline Cenário I & Cenário II & Cenário III \\
\hline Demanda 1 & $-0,404$ & $-0,404$ & $-0,404$ \\
Demanda 2 & $-0,404$ & $-0,404$ & $-0,404$ \\
Demanda 3 & $-0,404$ & $-0,404$ & $-0,404$ \\
\hline
\end{tabular}

Fonte: Elaboração própria a partir dos Gráficos 1, 2, 3, 4, 5, 6, 7, 8 e 9.

Os resultados mostram o efeito de alterações em $g, \pi^{*}$ e $r$ sobre o saldo primário do governo necessário para estabilizar a proporção dívida/PIB. O comportamento da política fiscal brasileira na fase pós-1999, a partir do modelo utilizado, permite afirmar que os resultados obtidos aderem ao comportamento da economia brasileira. O País apresentou reduzidas taxas de crescimento na atividade econômica, elevações constantes na taxa SELIC e a busca por metas de inflação cada vez menores para a taxa de inflação. Para tentar manter a dívida pública estável, é necessário preservar o esforço fiscal. O modelo aqui utilizado dá destaque, também, à demanda por títulos da dívida pública para que tal esforço fiscal seja aliviado, mostrando que uma taxa maior de acumulação desses títulos possibilita alívio nas contas do setor público. Portanto, há necessidade de se constituir um mercado de títulos públicos de liquidez elevada para minimizar o ajuste fiscal necessário para estabilizar a proporção dívida/ $\mathrm{PIB}$, além de manter as expectativas de pagamento futuro. 


\subsection{Saldo Primário do Governo e o Efeito de Choques Cambiais}

Até aqui, foi deixado de lado o impacto das variações cambiais sobre a dívida pública. Na tentativa de medir o efeito dos choques na taxa de câmbio sobre o esforço fiscal necessário para manter a relação dívida/PIB estável, iremos reescrever a equação (13) da seguinte forma:

$$
\frac{s p_{t}}{Y_{t}}=\left[\left\{\psi-r_{t}\right\}\left(\frac{B_{0}}{Y_{0}}\right) e^{(\psi-g-\pi)(t-1)}\right]\left[\frac{1}{(1+g+\pi)}\right]+\left(g+\pi^{*}\right)\left(\frac{H_{0}}{Y_{0}}\right)
$$

Pela equação (14), ao invés de decompor a dívida pública em interna e externa, estamos assumindo uma dívida pública total, $\left(\frac{B_{0}}{Y_{0}}\right)$, com uma respectiva demanda por títulos da dívida pública dada por $\psi$.

Para medir o comportamento da taxa de câmbio $\varepsilon_{t}$, assim como a magnitude de seus choques, podemos estabelecer a seguinte equação:

$$
\varepsilon_{t}=\varepsilon^{*}+\left(\bar{\varepsilon}-\varepsilon^{*}\right) e^{-\gamma t}
$$

onde $\varepsilon^{*}$ é a taxa de câmbio de equilíbrio, $\bar{\varepsilon}$ é a taxa de câmbio após o choque cambial e $\gamma$ um parâmetro que mede a velocidade de ajustamento da taxa de câmbio após o choque cambial para que esta atinja seu valor de equilíbrio, $\varepsilon^{*}$. Logo, com estas especificações, podemos medir o impacto do choque cambial sobre o esforço fiscal requerido para estabilizar a relação dívida/PIB com a desvalorização cambial da seguinte forma:

$$
\frac{s p_{t}}{Y_{t}}=\left[\left\{\psi-r_{t}\right\}\left(\frac{B_{0}}{Y_{0}} \cdot \varepsilon_{t}\right) e^{(\psi-g-\pi)(t-1)}\right]\left[\frac{1}{(1+g+\pi)}\right]+\left(g+\pi^{*}\right)\left(\frac{H_{0}}{Y_{0}}\right)
$$

Com esta equação, a Tabela 5 traz os resultados do superávit primário necessário para estabilizar a relação dívida/PIB considerando diferentes valores para os choques na taxa de câmbio. Na construção dessas trajetórias, foram assumidas três hipóteses em relação aos parâmetros especificados no Quadro 1: primeiro, nossa nova variável, $\gamma$, assume um valor de 0,3 ; segundo, para simplificar a análise, a taxa de câmbio de equilíbrio é 1 (um); terceiro, a relação dívida total/PIB é de 0,5 . 
TABELA 5 - TRAJETÓRIA DO SALDO PRIMÁRIO DO GOVERNO (\%PIB) NECESSÁRIO PARA A ESTABILIDADE DA PROPORÇÃO DÍVIDA/ PIB SOB DEMANDAS PELOS TÍTULOS DA DÍVIDA PÚBLICA ALTERNATIVOS CONSIDERANDO DIFERENTES TAXAS DE VARIAÇÃO CAMBIAL

\begin{tabular}{|c|c|c|c|c|c|c|}
\hline \multirow{2}{*}{ Tempo (anos) } & \multicolumn{6}{|c|}{ Variação Cambial } \\
\hline & $5 \%$ & $7 \%$ & $9 \%$ & $11 \%$ & $15 \%$ & $20 \%$ \\
\hline \multicolumn{7}{|c|}{ Demanda 1} \\
\hline 1 & 8,33 & 8,46 & 8,58 & 8,71 & 8,96 & 9,27 \\
\hline 5 & 5,08 & 5,11 & 5,13 & 5,16 & 5,20 & 5,27 \\
\hline 10 & 2,73 & 2,73 & 2,73 & 2,74 & 2,74 & 2,75 \\
\hline \multicolumn{7}{|c|}{ Demanda 2} \\
\hline 1 & 4,27 & 4,34 & 4,41 & 4,47 & 4,61 & 4,78 \\
\hline 5 & 4,15 & 4,17 & 4,19 & 4,21 & 4,25 & 4,30 \\
\hline 10 & 4,11 & 4,11 & 4,12 & 4,12 & 4,13 & 4,14 \\
\hline \multicolumn{7}{|c|}{ Demanda 3} \\
\hline 1 & 3,74 & 3,80 & 3,87 & 3,93 & 4,05 & 4,20 \\
\hline 5 & 3,64 & 3,66 & 3,68 & 3,69 & 3,73 & 3,78 \\
\hline 10 & 3,60 & 3,61 & 3,61 & 3,62 & 3,62 & 3,64 \\
\hline \multicolumn{7}{|c|}{ Demanda 4} \\
\hline 1 & 3,23 & 3,29 & 3,34 & 3,39 & 3,50 & 3,63 \\
\hline 5 & 3,14 & 3,16 & 3,17 & 3,19 & 3,22 & 3,26 \\
\hline 10 & 3,11 & 3,11 & 3,12 & 3,12 & 3,13 & 3,14 \\
\hline
\end{tabular}

Fonte: Elaboração própria a partir da equação 16.

Os principais resultados do impacto dos choques cambiais sobre o esforço fiscal, mostrados na Tabela 5 e Gráfico 4 são:

- quanto maior a propensão de acumulação dos títulos, menor deverá ser o esforço fiscal, de modo que mudanças na demanda pelos papéis deslocam a curva que relaciona superávit primário e variação cambial;

- mudanças na taxa de variação cambial geram mudanças no esforço fiscal, de modo que quanto maior os choques cambiais - maiores desvalorizaçóes cambiais, maior será o superávit primário para manter estável a relação dívida/PIB. 
GRÁFICO 4 - ESFORÇO FISCAL E VARIAÇÃO CAMBIAL

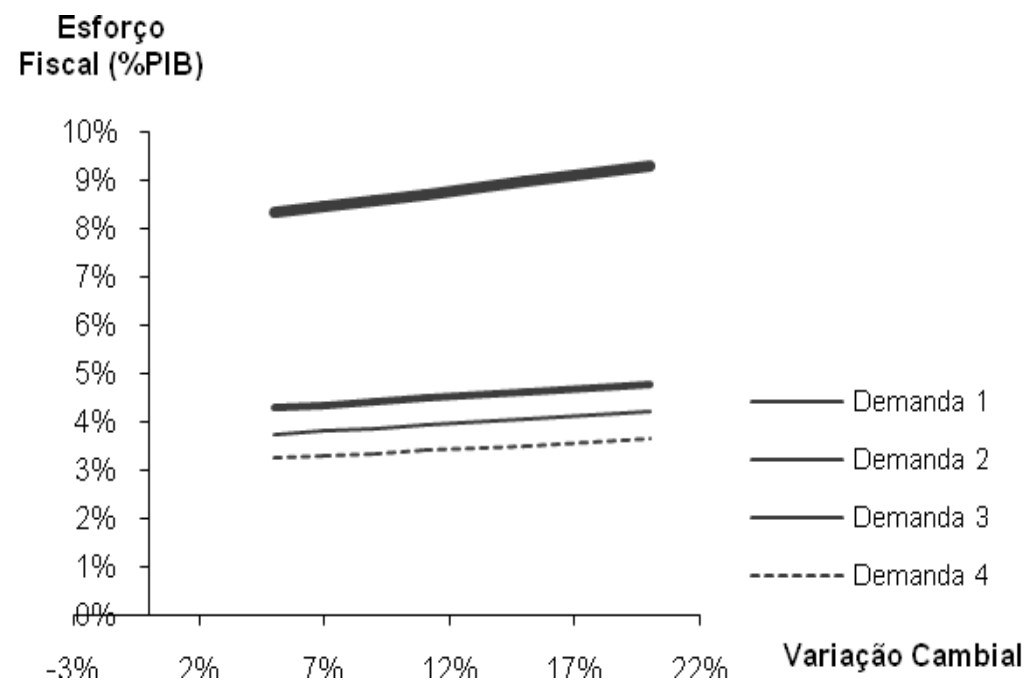

A magnitude do impacto de mudanças na demanda por títulos da dívida pública sobre o esforço fiscal requerido para estabilizar a proporção dívida/PIB para diferentes valores na variação do câmbio pode ser vista na Tabela 7. Percebe-se que a sensibilidade do superávit primário do governo é menor quanto maior a demanda pelos títulos públicos.

TABELA 6 - SENSIBILIDADES DO ESFORÇO FISCAL NECESSÁRIO PARA ESTABILIZAR A PROPORÇÃO DÍVIDA/PIB EM RELAÇÃO A CHOQUES NO CAMMBIO A PARTIR DE DIFERENTES DEMANDAS PELOS TÍTULOS DA DÍVIDA PÚBLICA

\begin{tabular}{cc}
\hline Demandas por Títulos Públicos & Sensibilidade Esforço Fiscal/ Câmbio \\
\hline Demanda 1 & 0,062 \\
Demanda 2 & 0,033 \\
Demanda 3 & 0,030 \\
Demanda 4 & 0,026 \\
\hline
\end{tabular}

Fonte: Elaboração própria a partir do Gráfico 4.

\section{CONSIDERAÇÕES FINAIS}

Neste artigo construíram-se várias trajetórias para o saldo primário do governo que auxiliam o entendimento da condução da política fiscal no Brasil. A necessidade de gerar superávits primários nas contas públicas está associada à manutenção de elevadas taxas de juros. Isto, além de gerar déficits fiscais, inibe o crescimento da 
atividade econômica. Para atender à condição de sustentabilidade da dívida pública, a política fiscal tem objetivado o incremento na arrecadação tributária, gerando superávits fiscais crescentes a partir de 1999.

O ajuste fiscal promovido a partir de 1999 foi importante, sobretudo em função do expressivo aumento do estoque da dívida pública, reflexo do uso das taxas de juros elevadas, necessárias para sustentar a âncora cambial até o esgotamento do regime de câmbio semifixo e déficits em transações correntes. Os resultados fiscais a partir de 1999 caracterizam desejável resistência à tentação de implementar políticas fiscais pró-cíclicas, o que é compatível com o regime de metas inflacionárias.

Queda na taxa de crescimento real do PIB, aumentos na taxa de remuneração dos títulos públicos e desvalorizações cambiais implicam a necessidade de gerar superávits primários crescentes para que a relação dívida/PIB permaneça estável, o que pode gerar dúvida sobre a manutenção dessa política em virtude do elevado esforço fiscal envolvido. Se não houver como acelerar o crescimento da economia ou reduzir os juros, mantendo metas de inflação ambiciosas, o controle do crescimento da dívida passará a depender do esforço fiscal.

Os resultados das simulações mostram que quanto maior a demanda pelos títulos públicos, menor será o esforço fiscal necessário ao atendimento da sustentabilidade da dívida pública, o que a princípio torna-se um instrumento alternativo para minimizar o custo social de manter elevados superávits primários.

Nas simulações, o aumento na taxa de acumulação dos títulos da dívida gerou aumento da sensibilidade do saldo primário necessário à estabilidade da relação dívida/ PIB em relação à taxa de crescimento real do PIB e a mudanças na taxa de câmbio. No caso da meta de inflação e da taxa de remuneração dos títulos, a mudança na demanda pelos papéis produziu menores superávits primários por meio de deslocamentos paralelos das curvas que relacionam $\left(\frac{s p_{t}}{Y_{t}}, \pi^{*}\right)$ e $\left(\frac{s p_{t}}{Y_{t}}, r\right)$. Esses resultados corroboram a idéia de que a existência de um mercado de títulos públicos de liquidez elevada, ao ter como efeito principal o aumento da negociabilidade, produz maior atratividade para os investidores, que gera um aumento na demanda pelos papéis, e se reflete em aumento nos preços dos títulos, ou seja, redução das taxas de juros.

Assim, os efeitos de uma ampliação na demanda pelos títulos da dívida pública, ao gerar possibilidades de um ritmo de crescimento mais elevado - devido a possíveis quedas na taxa de juros e com isso um maior estímulo para a atividade real da economia - proporcionam também a redução do serviço da dívida pública. Além disso, 
possibilitam maior coordenação com a política monetária, pois dão maior margem para o Banco Central operar o sistema de metas inflacionárias, já que uma possível ampliação na liquidez dos títulos possibilita reduções nas taxas de juros, induzindo menor custo para a atividade econômica quando for necessária a ampliação dos juros em caso de choques inflacionários.

A contribuição deste trabalho foi construir várias trajetórias para o saldo primário do governo que auxiliam o entendimento da condução da política fiscal no Brasil. A novidade neste estudo empírico foi analisar o impacto das principais variáveis macroeconômicas sobre a sustentabilidade do endividamento público brasileiro. $\mathrm{O}$ principal resultado empírico do estudo mostrou que além da preocupação com a sustentabilidade da dívida, a política fiscal no Brasil deve ter como foco mecanismos que possam ampliar a liquidez dos títulos públicos, pois o aumento da demanda pelos papéis tende a minimizar o esforço fiscal requerido para estabilizar a proporção dívida/PIB. Contudo, em função da própria natureza dos exercícios de estática comparativa utilizados, o trabalho limita-se a investigar possíveis mecanismos que possam analisar o mercado de títulos públicos no País. Por exemplo, o mercado de títulos públicos brasileiros tem hoje liquidez bastante elevada principalmente para títulos atrelados à taxa Selic (pós-fixados) ou prefixados de prazos curtos. Esse é atualmente um dos principais problemas do gerenciamento da dívida pública brasileira. Essa problemática seria interessante para aprimorar as discussões aqui efetuadas.

\section{REFERENNCIAS}

BATISTA JR., Paulo N. Ajustamento das contas públicas na presença de uma dívida elevada: observações sobre o caso brasileiro. Revista de Economia Política, v. 9, n. 4, p. 70-87, out-dez. 1989.

BEVILAQUA, A. S.; WERNECK, R. L. F. Public-sector debt dynamics in Brazil. PUC-RIO, Departamento de Economia, out. 1997. (Texto para Discussão, n. 376).

BORGES, Bráulio de Lima. Sustentabilidade e limites de endividamento público: o caso brasileiro. Brasília: ESAF, 2006.

BUITER, W. Guide to public sector debt and deficits. Economic policy: a European Forum, 1, p. 13-79, nov. 1985.

EDWARDS, Sebastian. Debt relief and fiscal sustainability. Review World Economics/ Weltwirtschaftliches, v. 139, n. 1, p. 38-65, 2003.

GAMBOA, Ulisses Ruiz de; SILVA, Roseli da. Nova evidência sobre a sustentabilidade da política fiscal brasileira: cointegração, quebras estruturais e senhoriagem. Seminários Bacen-USP de Economia Monetária e Bancária, 2004. 
GIAMBIAGI, Fabio; RONCI, Marcio. Fiscal policy and debt sustainability: Cardoso's Brazil, 1995-2002. IMF Working Paper, WP/04/156, Aug. 2004.

HERMANN, Jennifer. A macroeconomia da divida pública: notas sobre o debate teórico e a experiência brasileira recente (1999-2002) - IE/UFRJ. Disponível em: <www.ie.ufrj.br/moeda/pdfs/a_macroeconomia_da_divida_publica.pdf > . Acesso em: 29 abr. 2004.

ISSLER, J. V.; LIMA, L. R. Public debt sustainability and endogenous seignorage in Brazil: time-series evidence from 1947-92. Rio de janeiro: FGV, jun. 1998. (Ensaios Econômicos da EPGE, 306).

LUPORINI, Viviane. A sustentabilidade da dívida mobiliária federal brasileira: uma investigação adicional. Revista Análise Econômica, ano 19, n. 36, p. 69-84, set. 2001 .

PASTORE, Affonso Celso. Déficit público, a sustentabilidade do crescimento das dívidas interna e externa, senhoriagem e inflação: uma análise do regime monetário brasileiro. Revista de Econometria, v. 14, n. 2, p. 177-234, nov.1994/mar.1995.

ROCHA, Fabiana. Long-run limits on the Brazilian government debt. Revista Brasileira de Economia. Rio de Janeiro, v. 51, n. 4, p. 447-470, out./dez. 1997.

ROMER, David. Advanced macroeconomics. 2. ed. New-York: McGraw-Hill, 2000. 